\title{
Non-surgical interventions for preventing contralateral tissue loss and amputation in dysvascular patients with a primary major lower limb amputation (Protocol)
}

De Siqueira J, Russell DA, Siddle HJ, Richards SH, McGinnis E

De Siqueira J, Russell DA, Siddle HJ, Richards SH, McGinnis E.

Non-surgical interventions for preventing contralateral tissue loss and amputation in dysvascular patients with a primary major lower limb amputation (Protocol).

Cochrane Database of Systematic Reviews 2021, Issue 1. Art. No.: CD013857.

DOI: 10.1002/14651858.CD013857. 
TABLE OF CONTENTS

HEADER 1

ABSTRACT

BACKGROUND

OBJECTIVES

METHODS

ACKNOWLEDGEMENTS

REFERENCES

ADDITIONAL TABLES

APPENDICES

HISTORY

CONTRIBUTIONS OF AUTHORS

DECLARATIONS OF INTEREST

SOURCES OF SUPPORT

NOTES 
[Intervention Protocol]

\section{Non-surgical interventions for preventing contralateral tissue loss and amputation in dysvascular patients with a primary major lower limb amputation}

Jonathan De Siqueira1 ${ }^{1}$, David A Russell2 ${ }^{2}$, Heidi J Siddle ${ }^{3}$, Suzanne H Richards ${ }^{4}$, Elizabeth McGinnis 5

1Leeds Institute of Cardiovascular and Metabolic Medicine, University of Leeds, Leeds, UK. 2Leeds Vascular Institute, Leeds Teaching Hospitals NHS Trust, Leeds, UK. ${ }^{3}$ Leeds Institute of Rheumatic and Musculoskeletal Medicine, University of Leeds, Leeds, UK. ${ }^{4}$ Leeds Institute of Health Sciences, University of Leeds, Leeds, UK. ${ }^{5}$ Clinical Trials Research Unit, University of Leeds, Leeds, UK

Contact address: Elizabeth McGinnis, e.mcginnis@leeds.ac.uk, elizabeth.mcginnis@nhs.net.

Editorial group: Cochrane Vascular Group.

Publication status and date: New, published in Issue 1, 2021.

Citation: De Siqueira J, Russell DA, Siddle HJ, Richards SH, McGinnis E. Non-surgical interventions for preventing contralateral tissue loss and amputation in dysvascular patients with a primary major lower limb amputation (Protocol). Cochrane Database of Systematic Reviews 2021, Issue 1. Art. No.: CD013857. DOI: 10.1002/14651858.CD013857.

Copyright @ 2021 The Cochrane Collaboration. Published by John Wiley \& Sons, Ltd.

\section{A B S T R A C T}

\section{Objectives}

This is a protocol for a Cochrane Review (intervention). The objectives are as follows:

To assess the effects of non-surgical interventions versus placebo, or no intervention, or other non-surgical interventions, on contralateral limb tissue loss and amputation in dysvascular patients with a primary major lower limb amputation. 


\section{B A C K G R O U N D}

\section{Description of the condition}

Major lower limb amputation (LLA) is a disabling operation carried out in patients with non-functional limbs which are not salvageable. It is defined as any amputation of the lower limb above the ankle (i.e. trans-tibial, through-knee, trans-femoral or hip disarticulation) (Vascular Society 2016). Approximately 7500 LLAs were carried out in England between 2015 and 2018 (Public Health England 2019). Global estimates in incidence of amputation are difficult to establish given significant variability in reporting outcomes and measures (Moxey 2011). The estimated cost to the United Kingdom's National Heath Service is over $£ 60$ million annually (Graz 2018). Studies assessing the quality of life scores of amputees reveal these to be significantly lower than those of the general population. Such differences are attributed to factors such as lack of employment, chronic pain and limitations on mobility (Sinha 2011).

Amputation is occasionally performed in the management of traumatic limb injury and cancer. However, it is more commonly performed in the management of dysvascular patients (dysvascular amputation) (Dillingham 2002). Dysvascularity is a term which refers to the absence of adequate blood supply to maintain a limb's usual function (ischaemia), ultimately leading to pain and tissue injury: breaks in the epithelial surface of the skin, which can penetrate to deeper tissues (ulceration) and necrosis or death of tissues (gangrene). These conditions are also included in the definition of chronic limb-threatening ischaemia. Dysvascularity, like ischaemia, may have one or more underlying causes, including atherosclerotic peripheral arterial disease (PAD), diabetic macro- and microvascular disease, small and large vessel vasculitides, vascular traumatic injury and acute embolic phenomena. Dysvascularity is generally a systemic state and will usually affect both lower limbs.

Among those who undergo LLA, 5.7\% and $11.5 \%$ will undergo contralateral LLA at one and five years, respectively (Glaser 2013), and 33\% will die within three years (Singh 2016). Dysvascularity due to PAD and diabetes is an independent predictor of contralateral limb (CLL) loss. NICE guidance does not have specific advice regarding prevention of LLA. However, there are two related guidelines: (NG19) Diabetic foot problems: prevention and management (NICE 2015) found effectiveness for multi-disciplinary teams for inpatients, clear protocols and pathways for a continued and integrated foot protection service, foot examination and certain foot orthoses, but no significant difference in effectiveness of patient education, augmented foot examination and other foot orthosis; (CG147) PAD: diagnosis and management (NICE 2012) reports ulceration as a symptom of PAD; however, prevention was outside of its remit. Additional searches for evidence of the effectiveness of interventions for primary LLA have found a paucity of studies. However, there is further evidence for the prevention of diabetic foot ulcers. For example, a Cochrane review of complex interventions for the prevention of diabetic foot ulcers found six low-quality studies that met their criteria, two of which had a significant reduction of foot ulceration or LLA or both (Hoogeveen 2015), and a systematic review of footwear and offloading interventions found sufficient good quality evidence to support the use of devices to prevent plantar/neuropathic foot ulcers but very little evidence for all other foot ulcers (e.g. those associated with PAD) (Bus 2016).
This review focuses on secondary prevention of complications of the CLL following a first major LLA because, although we know indications for the CLL loss are the same as for primary amputation (critical limb ischaemia), bilateral amputees require significantly more energy to mobilise and have much poorer functional status than do unilateral amputees (Akarsu 2013). Local audits have also shown that there is an exceptionally high risk of ulceration or LLA of the CLL or both, that care of the CLL is sub-standard and patients have told us that whilst highly motivated to preserve the CLL they receive little information/support, and the impact on QoL, mortality and health care costs greatly increase following amputation of the CLL.

\section{Description of the intervention}

There is currently no accepted standard for the care of the CLL in unilateral amputees. Patients will not necessarily receive regular follow-up after LLA. Whilst a number of interventions already exist which are typically used in the prevention of primary amputation and the management of tissue injury in dysvascular patients, these are naturally also used in the prevention of contralateral tissue injury and limb loss.

Interventions for the prevention of limb loss may be:

- physical (e.g. offloading pressure from the foot or applying skin protection);

- pharmacological (e.g. prostanoids, antiplatelet and cholesterollowering treatment for PAD);

- educational (e.g. education of staff, patients or carers in prevention strategies);

- behavioural (e.g. motivating and refocusing patients following their primary LLA to care for their CLL);

- organisational (e.g. care pathways, audit standards which aim to improve outcomes for the CLL).

\section{How the intervention might work}

Pressure-offloading interventions aim to alter the biomechanics of gait and to reduce static pressure on the foot. They are typically used in the management of ulceration, as direct pressure is believed to contribute to the mechanical breakdown of skin and plantar fat, particularly in dysvascular patients with neuropathy and foot deformity. They have been shown to promote ulcer healing in two meta-analyses (Elraiyah 2016; Morona 2013); by inference, they may affect (contralateral) limb loss but the evidence for this is less established. Topical treatments (dressings, creams) to damaged or ulcerated skin are viewed as an important aspect of all ulcer management, irrespective of location or underlying aetiology. Protecting the skin from excess moisture, bacterial colonisation and other deleterious factors should promote its normal functioning and healing (Dumville 2013; Nolan 2012).

Pharmacological interventions modulate the pathological vascular biological state underlying dysvascularity. The presumed utility in their use in PAD is extrapolated from coronary disease and stroke (Chou 2016; Ma 2019). However, antiplatelet medication and cholesterol-lowering drugs have been demonstrated to stabilise atherosclerotic disease (Cyrus 2002; Libby 2003). By inference, they may prevent the evolution of a critically ischaemic state in the peripheral circulation.

Non-surgical interventions for preventing contralateral tissue loss and amputation in dysvascular patients with a primary major lower

limb amputation (Protocol)

Copyright (C) 2021 The Cochrane Collaboration. Published by John Wiley \& Sons, Ltd. 
Education of staff, patients and carers aims to alert them to early and critical signs of limb-threatening dysvascularity (Dorresteijn 2014). Such education may bring about timely intervention to prevent further deterioration and limb loss. Behavioural interventions aim to modify patients' lifestyle decisions, including medication compliance and blood glucose control, which are established risk factors for the progression of disease (Boyko 2018). Lastly, organisational interventions aim to improve patient pathways, reduce waiting times and promote targeted review in order to alter outcomes (NICE 2015).

\section{Why it is important to do this review}

Undergoing a bilateral amputation is associated with both poorer functional status and physical ability than that experienced by patients who have had unilateral amputation. However, there is a lack of clarity and paucity of evidence to suggest how to prevent patients progressing from unilateral to bilateral amputation; the degree to which the effectiveness of interventions tested in primary prevention settings translate into improved outcomes in this group of patients is unknown. The need for this review was identified following an ongoing National Institute for Health Research (NIHR) Programme Grant for Applied Health Research (PGfAHR) application, a retrospective review of the care of patients following major limb amputation and a consultation with a local patient group who highlighted a lack of advice and interventions for their CLL following major limb amputation.

This review is likely to benefit vascular surgeons, podiatrists, orthotists, nursing staff, physiotherapists, occupational therapists and rehabilitation specialists who care for and manage dysvascular patients who have undergone a major LLA, as it will inform their practice. It will also benefit the patient population described by aiding decision making and improving their caregivers' and health care teams' ability to care for them effectively. It hopes to benefit policy makers by identifying clinically effective interventions and directing future guidelines for the care of dysvascular patients.

\section{OB JECTIVES}

To assess the effects of non-surgical interventions versus placebo, or no intervention, or other non-surgical interventions, on contralateral limb tissue loss and amputation in dysvascular patients with a primary major lower limb amputation.

\section{METHOD S}

\section{Criteria for considering studies for this review}

\section{Types of studies}

We will include all randomised controlled trials (RCTs) and quasiRCTs (e.g. randomised by birth date) that compare the effectiveness of a non-surgical intervention with placebo, or no intervention, or other non-surgical intervention, on the development of localised tissue injury in dysvascular patients undergoing a primary major LLA. RCT designs can include individual or cluster randomisation.

\section{Types of participants}

We will include adults (18 years or older) who have had a primary major LLA (as defined above (Vascular Society 2016)) due to dysvascularity, including atherosclerotic PAD, diabetic macro- and microvascular disease and small and large vessel vasculitides. Participants will be adults from the point of decision to have a primary major LLA. There will be no restriction on gender, race or educational status, care setting (hospital, community, care home) or country. We will exclude participants who have had a primary major LLA solely due to trauma or malignancy.

\section{Types of interventions}

We will include any non-surgical intervention delivered by any healthcare worker, including doctors, nurses, physiotherapists, podiatrists, healthcare assistants and carers, with the aim of preventing ulceration or amputation of the CLL. Interventions may be:

- physical (e.g. offloading the foot, applying emollients);

- pharmacological (e.g. prostanoids, antiplatelet and cholesterollowering treatment for peripheral atherosclerotic disease);

- educational (e.g. education of staff, patients or carers in prevention strategies);

- behavioural (e.g. motivating and refocusing patients following their primary LLA to care for their CLL);

- organisational (e.g. care pathways, audit standards which aim to improve outcomes for the CLL).

Interventions can be delivered as a 'one time', 'repeated' or 'ongoing' intervention. They may be delivered at the time of the primary major LLA or any time following. They may be delivered singularly or as part of a complex intervention package.

We will also identify and report on any measures of adherence or compliance with interventions and their findings.

We will include the following comparisons:

- non-surgical intervention (physical, pharmacological, educational, behavioural or organisational) versus placebo;

- non-surgical intervention (physical, pharmacological, educational, behavioural or organisational) versus no intervention;

- non-surgical intervention (physical, pharmacological, educational, behavioural or organisational) versus standard care;

- non-surgical intervention (physical, pharmacological, educational, behavioural or organisational) versus nonsurgical intervention (physical, pharmacological, educational, behavioural or organisational).

As there is no accepted 'standard care' of the CLL, our initial categorisation will be based on study authors' reports. If overlap is later identified between intervention categories and comparators, re-categorisation may be necessary.

\section{Types of outcome measures}

\section{Primary outcomes}

- Incidence of new localised tissue injury, or ulceration, of the CLL, regardless of stage or classification at given time points;

- Time to development of any localised tissue injury, or ulceration, of the CLL, regardless of stage or classification;

- Incidence of new minor amputation (through the ankle, foot or toe(s)) (Vascular Society 2016) of the CLL at given time points;

- Time to new minor amputation (through the ankle, foot or toe(s)) (Vascular Society 2016) of the CLL;

Non-surgical interventions for preventing contralateral tissue loss and amputation in dysvascular patients with a primary major lower 
- Incidence of new major amputation (whole limb or partial limb, above the ankle) (Vascular Society 2016) of the CLL at given time points;

- Time to new major amputation (whole limb or partial limb, above the ankle) (Vascular Society 2016) of the CLL.

\section{Secondary outcomes}

- Survival (time to death from all causes);

- Patient-reported outcome measures of Health Related Quality of Life (HRQoL) using validated scales such as SF12 (Ware 1996), EQ 5D (EuroQol Group 2015);

- Adverse events (e.g. infections in the CLL);

- Hospital readmission.

We plan to record the latest time point given for study follow-up and 12 months post-primary major LLA, but we will be guided by the time points used in the individual studies. If other clinically important outcomes are measured, the reviewers will consider these for inclusion.

\section{Search methods for identification of studies}

\section{Electronic searches}

The Cochrane Vascular Information Specialist aims to identify all relevant RCTs regardless of language or publication status (published, unpublished, in press or in progress).

The Information Specialist will search the following databases for relevant trials:

- the Cochrane Vascular Specialised Register via the Cochrane Register of Studies (CRS-Web);

- the Cochrane Central Register of Controlled Trials (CENTRAL) via the Cochrane Register of Studies Online (CRSO);

- Medline (Ovid MEDLINE ${ }^{\circledR}$ Epub Ahead of Print, In-Process \& Other Non-Indexed Citations, Ovid MEDLINE ${ }^{\circledR}$ Daily and Ovid MEDLINE ${ }^{\circledR}$ ) (1946 onwards);

- Embase Ovid (from 1974 onwards);

- CINAHL EBSCO (from 1982 onwards);

- PEDro (the Physiotherapy Evidence database).

The Information Specialist has devised a draft search strategy for RCTs for MEDLINE which is displayed in Appendix 1. This will be used as the basis for search strategies for the other databases listed.

The Information Specialist will search the following trials registries:

- the World Health Organization International Clinical Trials Registry Platform ((WHO ICTRP; who.int/trialsearch);

- ClinicalTrials.gov (clinicaltrials.gov).

\section{Searching other resources}

We will examine the bibliographies of all studies identified for references to other relevant studies. We will contact specialists in the field and manufacturers of dressings, offloading devices (e.g. Smith and Nephew, Colplast, Convatec, Molnlycke, Urgo Medical, Frontier Medical Group, DM Systems, Posey, Covidien, Sundance Solutions, Anatomical Concepts Inc., Promedics, Streifeneder, Ossur, Steeper) and drugs (Bristol-Myers Squibb, Bayer, AstraZeneca, Pfizer) and authors of included studies for any unpublished data that report at least one of our primary outcomes.

\section{Data collection and analysis}

\section{Selection of studies}

We will illustrate the study selection process in a Preferred Reporting Items for Systematic reviews and Meta-Analyses (PRISMA) diagram (Liberati 2009).

Two review authors (JD, EM) will independently screen the titles and abstracts from the search results to identify potential studies for inclusion. We will retrieve the full text of all potentially relevant studies to check compliance with the eligibility criteria. We will consult one of the other review authors (DR) in case of disagreement. We will list all articles excluded after full-text assessment in a 'Characteristics of excluded studies' table and will provide the reasons for their exclusion.

\section{Data extraction and management}

Two review authors (JD, EM) will independently extract data and record in the data collection form. We will consult one of the other review authors (DR) in case of disagreement. The information collected will include: study publication details, design, details of population, inclusion and exclusion criteria, intervention, numbers of participants in each group, duration of treatment and follow-up, outcomes and adverse events.

\section{Assessment of risk of bias in included studies}

Two review authors (JD, EM) will independently perform a risk of bias assessment of each included study and present each in a 'Risk-of-bias table' in accordance with the guidance in the Cochrane Handbook for Systematic Reviews of Interventions (Higgins 2011b). We will consult one of the other review authors (DR) in case of disagreement. We will contact study authors if clarification is needed to better assess risk of bias. Where cluster RCTs are identified, they will be examined for risk of bias due to recruitment bias, baseline imbalance, loss of clusters, incorrect analysis and comparability with single RCTs (Higgins 2011c).

\section{Measures of treatment effect}

We will calculate and report hazard ratios (HRs) with 95\% confidence intervals (Cls) for studies with time-to-event (and survival) outcomes, risk ratios (RR) with $95 \% \mathrm{Cls}$ for studies with dichotomous outcomes such as incidence or number of events at a given time. We will consider HRQoL outcome scales continuous data and analysed them using mean difference (MD) or standardised mean difference (SMD), both with $95 \% \mathrm{Cls}$, if different scales are used.

\section{Unit of analysis issues}

The unit of analysis will be the participant; however, in studies where ulceration and amputation of the same limb are reported, they will be treated as independent events (with adjustment for confounding in the analysis). We will record whether trials reported outcomes in terms of participant, limb, lesion/ulcer or multiple events such as ulcers or amputations. Where cluster trials are included, we will record whether the analysis has been conducted correctly (e.g. use methods that adjust for clustering and report this in the 'risk-of-bias table'). Where analysis has not been conducted correctly, we will, if possible, re-analyse the data. If re-analysis is not possible, we will present the outcome data separately. We will consider cross-over trials that report data prior to cross over, and we will only analyse data before cross over. 


\section{Dealing with missing data}

We will contact the study authors to retrieve any missing data, and we will report all data. In cases of insufficient responses, we will consider and report the available data and the impact on the risk of bias. Where possible, we will report analysis on an 'intentionto-treat' (ITT) basis. If full outcome data are not available, we will compare the effects using a best and worst case scenario as suggested in the Cochrane Handbook for Systematic Reviews of Interventions (Higgins 2011a).

\section{Assessment of heterogeneity}

We will consider clinical and statistical heterogeneity between studies. Clinical variability in interventions and outcomes are likely, given the broad scope of the review, and where appropriate will be presented and analysed separately. We will assess statistical heterogeneity using the chi-squared test with a significance of $\mathrm{P}<$ 0.1 and the 12 statistic. 12 statistic values of greater than $50 \%$ may indicate a substantial level of heterogeneity. If this is the case, we will perform any pooling using a random-effects model. For values of $\mathrm{I}$ less than $50 \%$, we will pool results using a fixed-effect model. If considerable heterogeneity (i.e. 1275 to $100 \%$ ) exists, we will not pool results, and we will report results narratively (Higgins 2011a).

\section{Assessment of reporting biases}

We will generate funnel plots and examine them for asymmetry to assess publication bias, if more than 10 studies are included, as suggested by the Cochrane Handbook for Systematic Reviews of Interventions (Higgins 2011a).

\section{Data synthesis}

We will present a narrative review of all the included studies. We will consider clinical, methodological and statistical heterogeneity and anticipate that these may be considerable in this review. If studies appear similar enough with respect to the type of intervention, duration of follow-up and outcomes reported, we will pool results for meta-analysis. We will use Review Manager 5 to synthesise any pooled data (Review Manager 2014). For dichotomous outcomes (relating to clinical events), we will use RR with 95\% Cl. For continuous data, we will use MD with $95 \% \mathrm{Cl}$, or, where an outcome was measured and reported in more than one way, an SMD with $95 \% \mathrm{Cls}$. We anticipate that we will use a random-effects model for any meta-analysis we are able to perform, however, if there are low levels of clinical and statistical heterogeneity, we will use a fixedeffect model of meta-analysis.

\section{Subgroup analysis and investigation of heterogeneity}

We plan to investigate the following subgroups, assuming sufficient data is available:

- diabetes versus no diabetes;

- effect of level of primary limb amputation (above knee amputation (AKA) vs. through or below knee amputation (TBKA));

- ambulatory status (walking with prothesis or ambulatory aid vs. restricted to chair/wheelchair/bed).

\section{Sensitivity analysis}

We will perform sensitivity analysis by excluding trials deemed to be at high risk of bias (i.e. more than two domains at high risk), if there are sufficient studies available.

\section{Summary of findings and assessment of the certainty of the evidence}

We will prepare 'Summary of findings' tables to present the key information from the review. We will use GRADEpro software to create the tables (GRADEpro GDT 2015). For each comparison, where possible, we will include the outcomes described in Types of outcome measures at a given time point (e.g. 12 months). We have identified the seven most clinically relevant outcomes as incidence of tissue injury or ulceration, time to tissue injury or ulceration, incidence of minor amputation, time to minor amputation, incidence of major amputation, time to major amputation, and survival. We will assess the certainty of the evidence using the GRADE approach (GRADE 2004) and judge the certainty of the evidence for each outcome as high-, moderate-, low- or very low-certainty based on the five GRADE criteria of risk of bias, inconsistency, indirectness, imprecision and publication bias. We have included an example 'Summary of findings' table (Table 1).

\section{ACKNOWLEDGEMENTS}

The authors and the Cochrane Vascular Editorial base are grateful to the following peer reviewers for their time and comments: Marc Schermerhorn, MD, George HA Clowes Jr. Professor of Surgery, Harvard Medical School, Boston, US; Mark E Huang, MD, Shirley Ryan Ability lab, Professor, Department of Physical Medicine and Rehabilitation, Northwestern University Feinberg School of Medicine, Chicago, US; Dr Richard A Frieden, MD, MS, Medical Director, Amputation Specialty Program, Icahn School of Medicine at Mount Sinai, New York, US; Stephana Cherak, MSc, PhD student, Cumming School of Medicine, University of Calgary, Calgary, Canada. 


\section{REFERE N CE S}

\section{Additional references}

\section{Akarsu 2013}

Akarsu S, Tekin L, Safaz I, Göktepe AS, Yazicioğlu K. Quality of life and functionality after lower limb amputations: comparison between uni- versus bilateral amputee patients. Prosthetics and Orthotics International 2013;37(1):9-13.

\section{Boyko 2018}

Boyko EJ, Seelig AD, Ahroni JH. Limb- and person-level risk factors for lower-limb amputation in the prospective Seattle Diabetic Foot Study. Diabetes Care 2918;41(4):891-8.

\section{Bus 2016}

Bus SA, van Deursen RW, Armstrong DG, Lewis JE, Caravaggi CF, Cavanagh PR. International Working Group on the Diabetic Foot. Footwear and offloading interventions to prevent and heal foot ulcers and reduce plantar pressure in patients with diabetes: a systematic review. Diabetes Metabolism Research and Reviews 2016;32 (Suppl 1):99-118. [DOI: 10.1002/dmrr.2702. PMID: 26342178]

\section{Chou 2016}

Chou R, Dana T, Blazina I, Daeges M, Jeanne TL. Statins for prevention of cardiovascular disease in adults. Journal of the American Medical Association 2016;316(19):2008-24.

\section{Cyrus 2002}

Cyrus T, Sung S, Zhao L, Funk CD, Tang S, Praticò D. Effect of low-dose aspirin on vascular inflammation, plaque stability, and atherogenesis in low-density lipoprotein receptor-deficient mice. Circulation 2002;106(10):1282-7.

\section{Dillingham 2002}

Dillingham TR, Pezzin LE, MacKenzie EJ. Limb amputation and limb deficiency: epidemiology and recent trends in the United States. Southern Medical Journal 2002;95(8):875-83.

\section{Dorresteijn 2014}

Dorresteijn JA, Kriegsman DM, Assendelft WJ, Valk GD. Patient education for preventing diabetic foot ulceration. Cochrane Database of Systematic Reviews 2014, Issue 12. Art. No: CD001488. [DOI: 10.1002/14651858.CD001488.pub5]

\section{Dumville 2013}

Dumville JC, O'Meara S, Deshpande S, Speak K. Hydrogel dressings for healing diabetic foot ulcers. Cochrane Database of Systematic Reviews 2013, Issue 7. Art. No: CD009101. [DOI: 10.1002/14651858.CD009101.pub3]

\section{Elraiyah 2016}

Elraiyah T, Tsapas A, Prutsky G, Domecq JP, Hasan R, Firwana B, et al. A systematic review and meta-analysis of adjunctive therapies in diabetic foot ulcers. Journal of Vascular Surgery 2016;63(2 Suppl):46S-58S.

\section{EuroQol Group 2015}

EuroQol Group. What is EQ-5D? euroqol.org/eq-5d/what-iseq-5d.html (accessed 4 June 2019).

\section{Glaser 2013}

Glaser JD, Bensley RP, Hurks R, Dahlberg S, Hamdan AD, Wyers MC, et al. Fate of the contralateral limb after lower extremity amputation. Journal of Vascular Surgery 2013;58(6):1571-7.

\section{GRADE 2004}

GRADE Working Group. Grading quality of evidence and strength of recommendations. BMJ 2004;328:1490-4.

\section{GRADEpro GDT 2015 [Computer program]}

McMaster University (developed by Evidence Prime) GRADEpro GDT. Version accessed 20 November 2018. Hamilton (ON): McMaster University (developed by Evidence Prime), 2015. Available from gradepro.org.

\section{Graz 2018}

Graz H, D'Souza VK, Alderson DEC, Graz M. Diabetes-related amputations create considerable public health burden in the UK. Diabetes Research and Clinical Practice 2018;135:158-65.

\section{Higgins 2011a}

Higgins JP, Green S, editor(s). Cochrane Handbook for Systematic Reviews of Interventions Version 5.1.0 (updated March 2011). The Cochrane Collaboration. 2011. Available from handbook.cochrane.org.

\section{Higgins 2011b}

Higgins JP, Altman DG, Sterne JAC, editor(s). Chapter 8: Assessing risk of bias in included studies: In: Higgins JP, Churchill R, Chandler J, Cumpston MS, editor(s), Cochrane Handbook for Systematic Reviews of Interventions. version 5.2.0 (updated June 2017). The Cochrane Collaboration, 2017. Available from www.cochrane.handbook.org (accessed 31 May 2019).

\section{Higgins 2011c}

Higgins JP, Deeks JJ, Altman DG, editor(s). Chapter 16: Special topics in statistics. In: Higgins JP, Churchill R, Chandler J, Cumpston MS, editor(s), Cochrane Handbook for Systematic Reviews of Interventions. version 5.2.0 (updated June 2017). The Cochrane Collaboration, 2017. Available from www.cochrane.handbook.org (accessed 31 May 2019).

\section{Hoogeveen 2015}

Hoogeveen RC, Dorresteijn JA, Kriegsman DM, Valk GD. Complex interventions for preventing diabetic foot ulceration. Cochrane Database of Systematic Reviews 2015, Issue 8. Art. No: CD007610. [DOI: 10.1002/14651858.CD007610.pub3]

\section{Libby 2003}

Libby P, Aikawa M. Mechanisms of plaque stabilization with statins. American Journal of Cardiology 2003;91(4A):4B-8B.

\section{Liberati 2009}

Liberati A, Altman DG, Tetzlaff J, Mulrow C, Gotzsche PC, Ioannidis JP, et al. The PRISMA statement for reporting systematic reviews and meta-analyses of studies that evaluate 
health care interventions: explanation and elaboration. PLOS Medicine 2009;6:e1000100.

\section{Ma 2019}

Ma TT, Wong ICK, Man KKC, Chen Y, Crake T, Ozkor MA, et al. Effect of evidence-based therapy for secondary prevention of cardiovascular disease: systematic review and meta-analysis. PLOS One 2019;14(1):e0210988.

\section{Morona 2013}

Morona JK, Buckley ES, Jones S, Reddin EA, Merlin TL. Comparison of the clinical effectiveness of different off-loading devices for the treatment of neuropathic foot ulcers in patients with diabetes: a systematic review and meta-analysis. Diabetes/ metabolism Research and Reviews 2013;29(3):183-93.

\section{Moxey 2011}

Moxey PW, Gogalniceanu P, Hinchliffe RJ, Loftus IM, Jones KJ, Thomson MM, et al. Lower extremity amputations - a review of global variability in incidence. Diabetic Medicine 2011;28:1144-53.

\section{NICE 2012}

National Institute of Health and Care Excellence. NICE guideline (CG147) Peripheral arterial disease: diagnosis and management. nice.org.uk/guidance/cg147 (accessed 28 October 2020).

\section{NICE 2015}

National Institute of Health and Care Excellence. NICE guideline (NG19). Diabetic foot problems: prevention and management. nice.org.uk/guidance/ng19 (accessed 4 June 2019).

\section{Nolan 2012}

Nolan K, Marmur E. Moisturizers: reality and the skin benefits. Dermatologic Therapy 2012;25(3):229-33.

\section{Public Health England 2019}

Public Health England, National Cardiovascular Intelligence Network (NCVIN). Diabetes foot care profile. https:// app.box.com/s/pmdl91gf2d6pscttb9avqwan6mcbs296/ file/432108631907 (accessed 4 June 2019).

\section{Review Manager 2014 [Computer program]}

Nordic Cochrane Centre, The Cochrane Collaboration Review Manager 5 (RevMan). Version 5.3. Copenhagen: Nordic Cochrane Centre, The Cochrane Collaboration, 2014.

\section{Singh 2016}

Singh RK, Prasad G. Long-term mortality after lowerlimb amputation. Prosthetics and Orthotics International 2016;40(5):545-51.

\section{Sinha 2011}

Sinha R, van den Heuvel WJ, Arokiasamy P. Factors affecting quality of life in lower limb amputees. Prosthetics and Orthotics International 2011;35(1):90-6.

\section{Vascular Society 2016}

Vascular Society of Great Britain and Ireland. A best practice clinical care pathway for major amputation surgery. Available at www.vascularsociety.org.uk/_userfiles/pages/files/Resources/ Vasc_Soc_Amputation_Paper_V2.pdf (accessed 4 June 2019).

\section{Ware 1996}

Ware J Jnr, Kosinski M, Keller SD. A 12-Item Short-Form Health Survey: construction of scales and preliminary tests of reliability and validity. Medical Care 1996;34(3):220-33.

\section{ADDITIONAL TABLES}

Table 1. Are non-surgical interventions more effective than standard care in preventing contralateral tissue injury or amputation?

\section{Non-surgical interventions compared with standard care for preventing contralateral (CLL) tissue injury or amputation}

Patient or population: adults who have had a primary major LLA due to dysvascularity

Settings: all care settings, including hospitals, community and care homes

Intervention: non-surgical interventions ${ }^{a}$

Comparison: standard careb

\begin{tabular}{|c|c|c|c|c|c|c|}
\hline \multirow[t]{2}{*}{ Outcomes } & \multicolumn{2}{|c|}{$\begin{array}{l}\text { Illustrative comparative risks }{ }^{\star}(95 \% \\
\mathrm{Cl})\end{array}$} & \multirow{2}{*}{$\begin{array}{l}\text { Relative ef- } \\
\text { fect } \\
(95 \% \mathrm{CI})\end{array}$} & \multirow{2}{*}{$\begin{array}{l}\text { No of } \\
\text { par- } \\
\text { tici- } \\
\text { pants } \\
\text { (stud- } \\
\text { ies) }\end{array}$} & \multirow[t]{2}{*}{$\begin{array}{l}\text { Certainty of the evidence } \\
\text { (GRADE) }\end{array}$} & \multirow[t]{2}{*}{$\begin{array}{l}\text { Com- } \\
\text { ments }\end{array}$} \\
\hline & $\begin{array}{l}\text { Assumed } \\
\text { risk with } \\
\text { standard } \\
\text { care }\end{array}$ & $\begin{array}{l}\text { Corresponding risk } \\
\text { with non-surgical in- } \\
\text { terventions }\end{array}$ & & & & \\
\hline & \multicolumn{2}{|c|}{ Study population } & & $\begin{array}{l}{[\text { val- }} \\
\text { ue] }\end{array}$ & $\begin{array}{l}\text { [Delete as } \\
\text { appropriate] }\end{array}$ & \\
\hline
\end{tabular}

Non-surgical interventions for preventing contralateral tissue loss and amputation in dysvascular patients with a primary major lower 
Table 1. Are non-surgical interventions more effective than standard care in preventing contralateral tissue injury or amputation? (Continued)

$\begin{array}{llll}\begin{array}{l}\text { Incidence of CLL } \\ \text { tissue injury/ulcer- } \\ \text { ation }\end{array} & \begin{array}{l}\text { [value] per } \\ \text { [value] per } \mathbf{1 0 0 0}\end{array} & \begin{array}{l}\text { RR [value] } \\ \text { ([value] to [value]) }\end{array} & \begin{array}{l}\text { ([value] to } \\ \text { [value]) }\end{array} \\ \text { [follow-up] } & & \end{array}$

$\begin{array}{ll}\text { ([val- } & \oplus \ominus \ominus \ominus \\ \text { ue]) } & \text { very low } \\ & \oplus \oplus \odot \odot \\ & \text { low }\end{array}$

$\oplus \oplus \oplus \ominus$

moderate

$\oplus \oplus \oplus \oplus$

high

\begin{tabular}{lll}
\hline Time to CLL tissue & \multicolumn{2}{l}{ Study population } \\
\cline { 2 - 3 } injury/ulceration & [value] per & [value] per 1000 \\
[follow-up] & $\mathbf{1 0 0 0}$ & ([value] to [value])
\end{tabular}

\begin{tabular}{|c|c|c|c|c|c|}
\hline \multirow{5}{*}{$\begin{array}{l}\text { Incidence of minor } \\
\text { amputation of the } \\
\text { CLL } \\
\text { [follow-up] }\end{array}$} & \multicolumn{2}{|c|}{ Study population } & \multirow{5}{*}{$\begin{array}{l}\text { RR [value] } \\
\text { ([value] to } \\
\text { [value]) }\end{array}$} & \multirow{5}{*}{$\begin{array}{l}\text { [val- } \\
\text { ue] } \\
\text { ([val- } \\
\text { ue]) }\end{array}$} & \multirow{2}{*}{$\begin{array}{l}\text { [Delete as } \\
\text { appropriate] } \\
\oplus \odot \odot \ominus \\
\text { very low }\end{array}$} \\
\hline & $\begin{array}{l}\text { [value] per } \\
1000\end{array}$ & $\begin{array}{l}\text { [value] per } 1000 \\
\text { ([value] to [value]) }\end{array}$ & & & \\
\hline & & & & & $\begin{array}{l}\oplus \oplus \ominus \ominus \\
\text { low }\end{array}$ \\
\hline & & & & & $\begin{array}{l}\oplus \oplus \oplus \ominus \\
\text { moderate }\end{array}$ \\
\hline & & & & & $\begin{array}{l}\oplus \oplus \oplus \oplus \\
\text { high }\end{array}$ \\
\hline
\end{tabular}

\begin{tabular}{|c|c|c|c|c|}
\hline \multirow{5}{*}{$\begin{array}{l}\text { Time to minor am- } \\
\text { putation of the } \\
\text { CLL } \\
\text { [follow-up] }\end{array}$} & Study population & \multirow{5}{*}{$\begin{array}{l}\text { HR [value] } \\
\text { ([value] to } \\
\text { [value]) }\end{array}$} & \multirow{5}{*}{$\begin{array}{l}\text { [val- } \\
\text { ue] } \\
\text { ([val- } \\
\text { ue]) }\end{array}$} & \multirow{5}{*}{$\begin{array}{l}\text { [Delete as } \\
\text { appropriate] } \\
\oplus \odot \ominus \ominus \\
\text { very low } \\
\oplus \oplus \ominus \odot \\
\text { low } \\
\oplus \oplus \oplus \odot \\
\text { moderate } \\
\oplus \oplus \oplus \oplus \\
\text { high }\end{array}$} \\
\hline & \multirow[t]{4}{*}{$\begin{array}{l}\text { [value] per } \mathbf{1 0 0 0} \\
\text { ([value] to [value]) }\end{array}$} & & & \\
\hline & & & & \\
\hline & & & & \\
\hline & & & & \\
\hline \multirow{2}{*}{$\begin{array}{l}\text { Incidence of major } \\
\text { amputation of the } \\
\text { CLL }\end{array}$} & Study population & \multirow{2}{*}{$\begin{array}{l}\mathbf{R R} \text { [value] } \\
\text { ([value] to } \\
\text { [value]) }\end{array}$} & \multirow{2}{*}{$\begin{array}{l}\text { [val- } \\
\text { ue] } \\
\text { ([val- } \\
\text { ue]) }\end{array}$} & \multirow{2}{*}{$\begin{array}{l}\text { [Delete as } \\
\text { appropriate] } \\
\oplus \ominus \ominus \ominus\end{array}$} \\
\hline & $\begin{array}{ll}\text { [value] per } & \text { [value] per } \mathbf{1 0 0 0} \\
\mathbf{1 0 0 0} & \text { ([value] to [value]) }\end{array}$ & & & \\
\hline
\end{tabular}

Non-surgical interventions for preventing contralateral tissue loss and amputation in dysvascular patients with a primary major lower 
Table 1. Are non-surgical interventions more effective than standard care in preventing contralateral tissue injury or amputation? (Continued)

[follow-up]

very low

$\oplus \oplus \ominus \ominus$

low

$\oplus \oplus \oplus \ominus$

moderate

$\oplus \oplus \oplus \oplus$

high

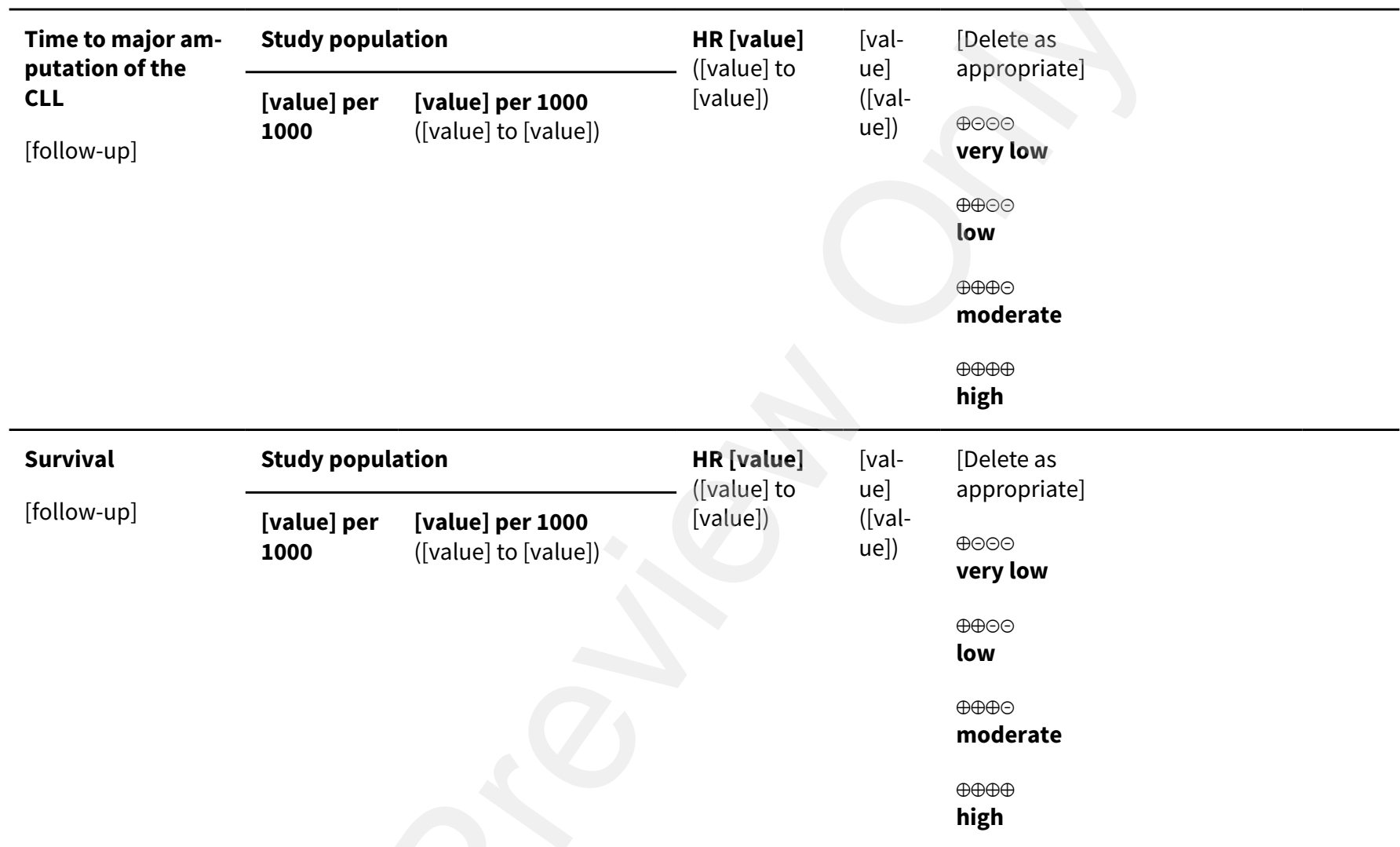

*The risk in the intervention group (and its $95 \%$ confidence interval) is based on the assumed risk in the comparison group and the relative effect of the intervention (and its $95 \% \mathrm{Cl}$ ).

Cl: confidence interval; CLL: contralateral limb; HR: hazard ratio; LLA: lower limb amputation; RR: risk ratio

\section{GRADE Working Group grades of evidence}

High certainty: We are very confident that the true effect lies close to that of the estimate of the effect

Moderate certainty: We are moderately confident in the effect estimate: The true effect is likely to be close to the estimate of the ef-

fect, but there is a possibility that it is substantially different

Low certainty: Our confidence in the effect estimate is limited: The true effect may be substantially different from the estimate of the effect

Very low certainty: We have very little confidence in the effect estimate: The true effect is likely to be substantially different from the estimate of effect

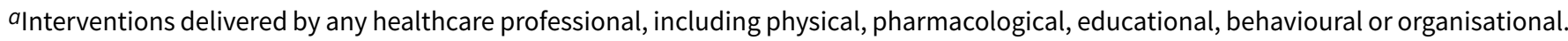
bStandard care is likely to include routine post-operative care and rehabilitation focusing on the primary LLA, without specific regard to the protection of the CLL. 


\section{AP PEN DICES}

\section{Appendix 1. MEDLINE search strategy}

1 Arterial Occlusive Diseases/

\section{ARTERIOLOSCLEROSIS/}

3 Arteriosclerosis Obliterans/

4 ARTERIOSCLEROSIS/

5 ATHEROSCLEROSIS/

6 exp Femoral Artery/

7 exp Iliac Artery/

8 exp LEG/bs [Blood Supply]

9 exp Peripheral Vascular Diseases/

10 exp Popliteal Artery/

11 exp Tibial Arteries/

12 Intermittent Claudication/

\section{ISCHEMIA/}

14 Vascular Diseases/

15 ((aort* or iliac or femoral or popliteal or femoro* or fempop* or crural) adj3 (obstruct* or occlus $\left.{ }^{\star}\right)$ ).ti,ab.

16 (arter* adj (occlus* or steno* or obstuct* or lesio* or block* or obliter*)).ti,ab.

17 (atherosclero* or arteriosclero* or PVD or PAOD).ti,ab.

18 (claudic* or hinken*).ti,ab.

19 ischemia*.ti,ab.

20 (leg adj4 (obstruct* or occlus* or steno* or block* or obliter $\left.{ }^{\star}\right)$ ).ti,ab.

21 (limb adj4 (obstruct* or occlus $^{\star}$ or steno* or block $^{\star}$ or obliter $\left.\left.{ }^{\star}\right)\right)$. ti,ab.

22 (lower adj3 extrem ${ }^{\star}$ adj4 (obstruct ${ }^{\star}$ or occlus ${ }^{\star}$ or steno* or block ${ }^{\star}$ or obliter ${ }^{\star}$ )).ti,ab.

23 (peripher ${ }^{\star}$ adj (occlus ${ }^{\star}$ or steno* or obstuct* or lesio* or block* or obliter $\left.{ }^{\star}\right)$ ).ti,ab.

24 (peripheral adj3 dis*).ti,ab.

25 (vascular adj (occlus* or steno* or obstuct $^{\star}$ or lesio* or block $^{\star}$ or obliter $\left.{ }^{\star}\right)$ ).ti,ab.

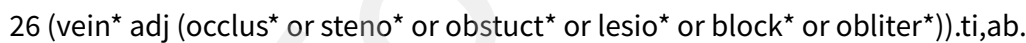

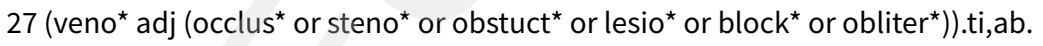

28 arteriopathic.ti,ab.

29 dysvascular ${ }^{\star}$.ti,ab.

30 or/1-29

31 exp Amputation/

32 exp Amputees/

33 amputat*.ti,ab.

Non-surgical interventions for preventing contralateral tissue loss and amputation in dysvascular patients with a primary major lower

Copyright $\odot 2021$ The Cochrane Collaboration. Published by John Wiley \& Sons, Ltd. 
34 amputee*.ti,ab.

35 disarticulat $^{\star} . t i, a b$.

36 exarticulat ${ }^{\star} . \mathrm{ti}, \mathrm{ab}$.

37 postamputation ${ }^{\star} . \mathrm{ti}, \mathrm{ab}$.

38 post-amputation ${ }^{\star} . t i, a b$.

39 "limb loss".ti,ab.

40 or/31-39

4130 and 40

42 randomized controlled trial.pt.

43 controlled clinical trial.pt.

44 randomized.ab.

45 placebo.ab.

46 drug therapy.fs.

47 randomly.ab.

48 trial.ab.

49 groups.ab.

50 or/42-49

51 exp animals/ not humans.sh.

5250 not 51

5341 and 52

\section{H I S T O R Y}

Protocol first published: Issue 1, 2021

\section{CONTRIBUTIONS OF AUTHORS}

JD: protocol drafting, acquiring trial reports, trial selection, data extraction, data analysis, data interpretation, review drafting and future review updates

DR: protocol drafting, data interpretation, review drafting and future review updates

HS: protocol drafting, data interpretation, review drafting and future review updates

SR: protocol drafting, data interpretation, review drafting and future review updates

EM: protocol drafting, acquiring trial reports, trial selection, data extraction, data analysis, data interpretation, review drafting, future review updates and guarantor of the review

\section{DECLARATIONSOF INTEREST}

JD: none known

DR: has declared that his institution received payment from URGO Medical and Integra Lifesciences (for membership of Diabetic Foot Advisory Board) and from URGO Medical (for his role as conference session chair and lectures on management of chronic wounds and diabetic foot ulcers). DR has also declared he is the Chief Investigator on a study (NIHR HTA Multiple interventions for diabetic foot ulcer treatment) and is the Principle Applicant (NIHR WoundTec HTC The use of Moleculight in the management of diabetic foot ulcers: a pilot study); and co-applicant (VASGBI NIAA The role of preoperative assessment in effective vascular multidisciplinary team decision making and randomised controlled trial of swab versus tissue sampling for infected diabetic foot ulcers, and comparison of culture versus molecular processing techniques).

HS: none known

SR: none known

Non-surgical interventions for preventing contralateral tissue loss and amputation in dysvascular patients with a primary major lower 
EM: has declared that her current post is funded indirectly through a research grant from the NIHR HTA programme for work on a RCT of interventions for diabetic foot ulcers.

\section{SOURCES OF SUPPORT}

\section{Internal sources}

- No sources of support supplied

\section{External sources}

- Chief Scientist Office, Scottish Government Health Directorates, The Scottish Government, UK The Cochrane Vascular editorial base is supported by the Chief Scientist Office.

\section{N O T E S}

Parts of the methods section of this protocol are based on a standard template established by the Cochrane Vascular Group. 